\title{
O Brasil através das histórias em quadrinhos de humor
}

\section{dos Santos, Roberto Elísio}

Resumen:

Este trabajo es el resultado de la investigación realizada en el Programa de Postgrado en Comunicación de la Universidad Municipal de São Caetano do Sul (USCS), en Brasil, cuyo objetivo es entender cómo la trayectoria política y social de Brasil fue retratada por dibujantes brasileños desde el siglo XIX hasta la contemporaneidad a través del humor. Para lograr este objetivo, una investigación documental y un análisis de contenidos y del contexto se llevó a cabo, así como la división en cinco grandes períodos en la historia del país y la producción de historietas.

Palabras clave: Historietas brasileñas humor gráfico - dibujo humorístico historia social y política - Brasil.

Cuadernos del Centro de Estudios de Diseño y Comunicación N ${ }^{074}$

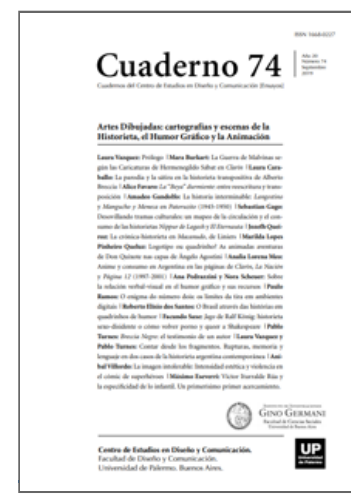

ISSN: 1668-0227

Artes Dibujadas:

cartografías y

escenas de la

Historieta, el Humor

Gráfico y la

Animación

Año XX, Septiembre 2019, Buenos

Aires, Argentina | 256 páginas

descargar PDF

ver índice de la publicación

Ver todos los libros de la publicación

compartir en Facebook

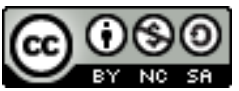

Esta obra está bajo una Licencia Creative Commons Atribución-NoComercialCompartirlgual 4.0 Internacional

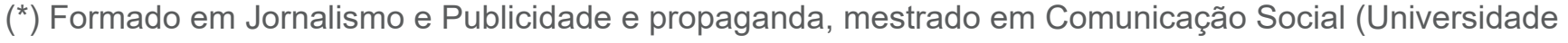
Metodista de São Paulo) e doutorado em Ciências da Comunicação (Universidade de São Paulo). Professor da Universidade Municipal de São Caetano do Sul. Pesquisador na área de história em quadrinhos. Vicecoordenador do Observatório de Histórias em Quadrinhos da Escola de Comunicações e Artes da Universidade de São Paulo

Introdução

O quadrinho, como narrativa sequencial gráfica, desenvolve uma história através da sucessão de imagens e textos, que deve ser lida em uma determinada ordem. Os conteúdos mais comunes deste produto midiático são humorísticos. Suas imagens e textos podem satirizar ou criticar as atitudes de personagens públicos ou ao ser humano comum. Segundo Moacy Cirne1, "não existem quadrinhos inocentes". Para este teórico, os quadrinhos procuram ocultar sua verdadeira ideologia através de uma fórmula simples ou simplista, e também de redundância. 
Portanto, este trabalho tem como objetivo apresentar uma visão geral do humor nas histórias em quadrinhos realizadas no Brasil e sua relação com o contexto histórico em que foram criadas (embora tenham sido criadas algumas tiras publicadas em jornais, o corpus deste estudo foi tomado principalmente de suplementos, revistas e álbuns de quadrinhos), tratando de entender como representam o país e os brasileiros. Este é o resultado de uma pesquisa qualitativa de nível exploratório que empregou as técnicas de levantamento documental (em acervos públicos e privados) y de análise de conteúdo e de contexto. Com base no material recolhido e nos estudos realizados, estabeleceram cinco períodos relevantes para os quadrinhos e para a história do país: a transição do Império para a República, os anos do pós-guerra (1945-1964), a ditadura militar (1964-1985), o momento da redemocratização e da crise econômica (1985-1995) e a passagem do século XX ao XXI com o uso da tecnologia digital.

Humor no Império e na República

A crítica ao governo, aos escândalos e aos abusos de poder dos governantes foi o material utilizado pelos periódicos que se multiplicaram em todo Brasil durante todo o século XIX. Ao lado dos textos acusatórios, desenhos humorísticos e caricaturas compõem o coro de indignação dos editores e artistas. Este procedimento havia se tornado comum na Europa: em 1832, o artista francês Charles Philipon lançou a revista La Caricatura e, nove anos mais tarde, apareceram na Inglaterra periódicos ilustrados, títulos que influenciaram os primeiros desenhistas brasileiros.

Não há consenso entre os pesquisadores brasileiros sobre o começo da caricatura no país, já que, antes de sua publicação em jornais, eram vendidas de forma fragmentada. Mas a publicação da caricatura política (que tratava de corrupção) feita en 1837 pelo pintor e poeta Manuel de Araújo Porto-Alegre, pode ser tomada como ponto de partida. Um dos artistas que empregaram o humor gráfico como uma forma de discurso político e crítico foi o ítalo-brasileiro Angelo Agostini. Nascido na Itália, ele estudou arte em Paris e chegou a Brasil com 16 anos. Suas caricaturas e desenhos humorísticos feitos na segunda metade do século XIX mostravam seu descontentamento com a monarquia. Sua carreira artística começou em 1864 no periódico Diabo Coxo, em São Paulo. Também trabalhou no jornal O Cabrião e, depois de mudar-se para o Rio de Janeiro, produziu desenhos para publicações como Vida Fluminense, O Mosquito e Don Quixote. Em 30 de janeiro de 1869, Agostini publicou o primeiro capítulo das Aventuras de Nhô Quim ou Impressões de uma viagem à Corte, mas só ilustrou nove páginas duplas que foram completadas por Candido Aragonez de Faria, artista que mais tarde se mudou para Buenos Aires.

Nhô Quim foi a primeira história longa de Agostini, publicada no periódico Vida Fluminense. A narrativa segue a trajetória de um caipira rico, desde sua saída da fazenda de seus pais no interior, até as confusões que apronta na cidade por não estar familiarizado com as convenções da vida urbana: o personagem causa acidentes de carruagens nas ruas do Rio de Janeiro, se surpreende com a luz elétrica e com o sorvete e é vítima de ladrões que desejam tomar seu dinheiro. $\mathrm{O}$ autor comicamente retrata a ingenuidade e a incapacidade do protagonista, ao mesmo tempo em que registra a forma de vida na segunda metade do século XIX, as transformações que estavam em marcha, a moda (Nhô Quim troca a roupa de camponês e as botas por uma vestimenta tipo "Dandy") e as convenções sociais.

Segundo Balaban2, há um consenso em considerar Agostini "uma mescla de artista e político, associação que definiria a caricatura como arte no século XIX". Para este autor, o artista "seria um dos pais da caricatura 
brasileira por ser feliz ao combinar seu talento empunhando o lápis com o ativismo político, sobretudo com respeito à abolição da escravatura e ao câmbio de regime político que a seguiu".

Em sua vida agitada, Agostini fundou em janeiro de 1876 a Revista Illustratada (que durou até 1888) e o periódico Don Quixote. Nas páginas da revista, este artista publicou a partir de 27 de janeiro de 1883, as aventuras de outro personagem, Zé Caipora, em 35 capítulos de páginas duplas, que foram reeditadas em Don Quixote e em O Malho. De modo diferente de Nhô Quim, Zé Caipora vive na cidade, mas como o primeiro, é também atrapalhado. Inicialmente, a história mostra as desventuras do protagonista azarado, que, em busca de fazer boa impressão na alta sociedade e, especialmente, aos olhos de sua amada, se converteu em uma vítima das zombarias dos outros, às vezes causando danos devido a sua própria inépcia. A história em quadrinhos humorística torna-se uma narrativa de aventuras quando o personagem viaja para o campo para ser curado de una enfermidade. Na floresta, frente a animais perigosos e a uma tribo de índios selvagens e com a colaboração da índia Inaiá, pode superar os obstáculos.

Sempre crítico, Agostini satirizava a vida no Rio de Janeiro, pregando o fim da escravidão e do regime monárquico -seus desenhos humorísticos e as caricaturas que fazia de Dom Pedro II, então imperador do Brasil, mostram a decadência do regime- e também passou a condenar os descaminhos da República recémproclamada. A colaboração para os quadrinhos brasileiros pode ser constatada, também, por sua participação $n$ a primeira publicação de quadrinhos dedicados às crianças, a revista O Tico-Tico, lançada em 1905. Para esta revista, Agostini elaborou o logotipo do título, capas, ilustrações e algumas narrativas sequenciais. Para a edição de O Tico-Tico número 5, de 8 de novembro de 1905, Agostini criou uma história para explicar aos mais jovens o que foi a escravidão no país.

Depois de Agostini, os desenhos de crítica política e social passaram pelas mãos de novos artistas: José Carlos de Brito e Cunha, mais conhecido pelo nome artístico de J. Carlos, foi ilustrador desde 1908 até 1922 da revista de humor A Careta. Este artista deixou impressa sua visão satírica dos fatos que afetaram o Brasil e o mundo, como a Primeira Guerra Mundial e as mudanças sociais e de comportamento. Além do humor político, também produziu peças de publicidade e criou quadrinhos infantis para a revista O Tico-Tico.

Ao lado de quadrinhos protagonizados por crianças (Chiquinho, Lamparina, Reco-Reco, Bolão e Azeitona, entre outros) e as histórias de aventura e de humor, O Tico-Tico oferecia a seus leitores jogos, contos e informação. Seus editores queriam levar o entretenimento e o conhecimento ao público infantil. Do ponto de vista do formato e da padronização gráfica, este periódico seguiu o modelo de revistas europeias da época, especialmente as publicações inglesas e francesas, como La Semaine de Suzette. Assim como na Europa, os quadrinhos publicados na revista brasileira traziam o texto impresso na parte inferior das vinhetas. No que se refere às questões formais e estéticas, o desenho segue, em grande parte, a tendência artística característica da Belle Époque, o estilo Art Nouveau, com suas curvas e cores frias.

Inicialmente, os quadrinhos publicados nas páginas de O Tico-Tico seguiram o gênero mais popular dos comics estadunidenses da época, estrelados por personagens infantis como The Yellow Kid e The Katzenjammer Kids. J. Carlos, por exemplo, criou vários personagens, como a menina negra Lamparina, que vive a fugir de casa, e o garoto Juquinha. As primeiras histórias em quadrinhos desta publicação ambientavam-se em um cenário rural, já que o processo de urbanização do país apenas começava. 
A edição número 1331 de O Tico-Tico, de 8 de abril de 1931, marcou a estreia das histórias protagonizadas por três meninos, Reco-Reco com seu cabelo espetado, o gordinho Bolão e o garoto negro Azeitona, criação de Luiz Sá, inicialmente com a colaboração de I. de Queiroz Galvão Neto. Também saiu da imaginação deste desenhista o papagaio Faísca, o detetive Pinga-Fogo e a garota negra Maria Fumaça. Seu estilo gráfico -com o corte nos olhos dos personagens e os braços que se dobram como tubos de borracha- foi influenciado pelos desenhos animados estadunidenses, como Mickey Mouse (de Ub Iwerks) e Betty Boop (dos Irmãos Fleischer).

Mas os quadrinhos publicados em O Tico-Tico não se limitaram a personagens infantis. Alfredo Storni criou em 1911 personagens Zé Macaco e Faustina, um casal marcado pela feiura e a estupidez, que, entretanto, queria mostrar-se sofisticado. Era uma crítica à classe média urbana, que surgiu no início do século XX. O par teve um filho, Baratinha, que apareceu brevemente nas histórias, que se centrava nos intentos fracassados da dupla para que fossem aceitos por el segmento mais rico da sociedade.

Desenhado por Max Yantok no mesmo ano que Zé Macaco y Faustina, o pseudoaventureiro Kaximbown e seu empregado Pipoca apareceram em histórias que geralmente ocupavam uma página (Ver Figura 2). Viajando pela misteriosa Pandegolândia, buscavam tesouros e caçavam animais selvagens, mas sempre terminavam por meter-se em confusões. Yantok também foi o autor das aventuras do Barão de Rapapé, de Chico Maldesorte, um mendigo azarado que vivia sem dinheiro, e os amigos Pandareco e Parachoque e seu cachorro Viralata.

Seguindo o mesmo caminho de J. Carlos, o desenhista Belmonte criou o personagem Juca Pato em 1925. Publicado nas páginas do periódico paulista Folha da Noite, o protagonista era um homem fraco, calvo, que se converteu no símbolo da população pobre, das pessoas comuns, cuja situação de pobreza é causada pela má gestão e pela corrupção dos poderosos. A partir de 1933, este artista fez para o suplemento de quadrinhos A Gazetinha as histórias dos garotos Paulinho y Albina.

Se a revista O Tico-Tico seguiu o modelo europeu de publicações impressas -especialmente o inglês e o francês-, A Gazeta Edição Infantil, mais conhecida como A Gazetinha, incorpora o formato dos suplementos publicados nos Estados Unidos e a estética e a linguagem dos comics estadunidenses. Nos quadrinhos produzidos então no Brasil, o uso de balões de fala tornou-se comum, em substituição aos textos colocados abaixo das vinhetas, o estilo gráfico adotado pelos artistas passou a ser mais realista, baseado no desenho de Hal Foster e Alex Raymond, e as narrativas de aventuras dividiam o espaço com as humorísticas. A Gazetinha surgiu em 1929 como uma seção do periódico de São Paulo A Gazeta, em 12 de setembro desse ano, e logo se converteu em um suplemento semanal. Além das tiras cômicas produzidas nos Estados Unidos (Félix The Cat, Little Nemo, Thimble Theater, entre outras), artistas brasileiros também elaboraram quadrinhos para este periódico: na edição número 5 debutou Piolim, desenhado por Gómez Dias e Nino Borges, personagem baseado no famoso palhaço brasileiro da época. Descontinuado em 1930, o suplemento passou a ser publicado de novo três anos mais tarde. Histórias de Betty Boop, Brick Bradford, The Phantom e Superman compartilhavam espaço con Nhô Totico, estrela de um programa brasileiro humorístico de rádio muito popular.

Dois artistas brasileiros se destacaram nas páginas deste suplemento: Belmonte e Messias de Mello. As narrativas de aventura de Messias eram serializadas em capítulos semanais de uma página (como Capitão Blood -quadrinização do livro escrito por Samuel Sabatini-, Sherlock Holmes, Homem Elétrico, etc.). Este artista foi o criador, em 1934, da história humorística protagonizada pelo Pão-Duro. Embora não seja sovina, este 
personagem arquitetava formas de ganhar dinheiro, normalmente junto a seu amigo Gibimba, mas suas ações sempre geravam confusões.

Os anos de pós-guerra (1945-1964)

No início da década de 1940 a influência dos Estados Unidos se acentuou ainda mais, sobretudo com a chamada "política da boa vizinhança" que pretendia cooptar países da América Latina para serem seus aliados na guerra. Neste contexto, o formato comic-book $(18,5 \times 26 \mathrm{~cm})$ se converteu no padrão para as histórias de revistas em quadrinhos brasileiras. Os primeiros a adotar foram os títulos Lobinho e Gibi. Na década de 1950, para reduzir os custos, alguns editores passaram para o formato digest (14 x 20,5 cm).

Outras faces do povo brasileiro, menos tímidos e servis, se mostraram através de personagens como 0 Amigo da Onça e Dr. Macarra (Ver Figura 3). Criado em 1943 por Pericles de Andrade Maranhão para o semanário $O$ Cruzeiro, um dos meios impressos mais influentes da época, O Amigo da Onça encarna o malandro sem caráter, mas amável e falador, que não perde a oportunidade de tomar vantagem sobre as debilidades dos demais. Este personagem utiliza-se de expedientes não para fins materiais, mas para superar outras pessoas, enganadas para satisfazer seu prazer sádico de exercer poder sobre os outros. Silva3 considera que as ações do personagem como uma relação de poder: a pessoa a ser derrotada sempre está em uma situação limite, e o protagonista se aproveita dela. Já Dr. Macarra, idealizado por Carlos Estêvão, vive jactando-se de mentiras inventadas para impressionar a seus ouvintes crédulos. A estrutura narrativa era invariável: na primeira vinheta, Macarra alardeia suas façanhas e, na seguinte, um flash-back revela ao leitor o que ocorreu na verdade.

Na década de 1950, a indústria cultural cresce no Brasil, com o início das transmissões de televisão e com a produção de comédias cinematográficas de grande atrativo popular. Vários quadrinhos passaram a ter como protagonistas os atores TV e do cinema, como a dupla Oscarito e Grande Otelo, o caipira Mazzaropi e os palhaços Arrelia e Pimentinha, que deleitavam as crianças. As histórias, desenhadas por Messias de Mello, João Batista Queiroz, Luiz Webster, Aylton Thomas, foram escritas por Alberto Maduar e as capas das revistas eram ilustradas por Jayme Cortez.

Para evitar que a aprovação de uma lei que obrigaria a publicação de quadrinhos brasileiros, os editores começaram a dar mais espaço a artistas que atuavam no Brasil. Assim, em 1960, a editora O Cruzeiro (que publicou revistas infantis como Guri) lançou Pererê, com personagens criados por Ziraldo Alves Pinto, inspirados no folclore e na fauna brasileira, em uma adesão clara à visão populista da época, que valorizava questões relacionadas à cultura do país.

No mesmo ano da aparição de Pererê, a editora Continental colocou a venda a revista Zaz Traz, na qual Mauricio de Sousa debutou com histórias do cachorro Bidú e de seu dono, o menino Franjinha. As primeiras tiras desses personagens haviam aparecido em 1959 no diário Folha de S. Paulo. No ano seguinte, o artista lançou a revista Bidú, que teve oito edições. Em 1963, inicialmente em tiras de jornal, Mauricio criou quadrinhos protagonizados pelas crianças Mônica, Cebolinha, entre outras, utilizando diversas vezes recursos de metalinguagem (com a linguagem das narrativas gráficas sequenciais) e de intertextualidade (com personagens de outras histórias, em especial os super-heróis). Os personagens desse artista, com exceção do caipira Chico Bento e do índio Papa-Capim, vivem em um ambiente urbano. 
A intenção de ampliar a publicação de quadrinhos brasileiros continuou na década de 1960, e uma das iniciativas mais importantes neste sentido ocorreu no Rio Grande do Sul. A CETPA - Cooperativa Editora de Trabalhos de Porto Alegre era responsável pelo lançamento de tiras e revistas de quadrinhos realizadas por vários artistas, com destaque para Zé Candango, desenhado por Renato Canini, cujo nome era uma homenagem aos construtores de Brasília, que migraram de suas cidades para trabalhar na construção da nova capital do país. Além desta referência, o personagem representa o povo brasileiro diante do imperialismo estadunidense: em uma sequência, o protagonista dá uma surra no Super Cabra (alusão a Superman, que representa, ao mesmo tempo, os comics estrangeiros e a força econômica e militar dos Estados Unidos). O caráter político da tira de quadrinhos está em consonância com as ideias nacionalistas e populistas da época. As atividades da CETPA foram interrompidas em 1963 por falta de uma melhor estrutura de publicação.

O humor durante a ditadura militar (1964-1985): contestação e censura

Com o golpe militar de 1964, o humor gráfico brasileiro voltou a satirizar a política nacional. Não obstante, com a crescente censura aos meios de comunicação, este tipo de material se restringiu à chamada "imprensa alternativa", como o semanário O Pasquim. Lan- çado em 1969, publicou as obras humorísticas e críticas feitas por Ziraldo, Jaguar, Henfil, entre outros artistas. Na década de 1970, a editora do periódico O Pasquim criou as revistas O Bicho e Fradim. Além dos quadrinhos de humor, a primeira revista, segundo Cirne4 , "também é importante por sua investigação arqueológica" de artistas brasileiros e de histó- rias nacionais do século XX. A segunda publicação, por sua vez, apresentava os personajes idealizados por Henfil (Henrique Filho), um artista que se opôs à ditadura. Seus tipos, como Os Fradinhos (Ver Figura 4), refletem a crítica política e social deste desenhista. Já Graúna, Zeferino e Bode Orelana denunciam a miséria do Nordeste e do povo brasileiro. Também em relação ao tema político, O Pato foi uma tira desenhada pela ilustradora Ciça (Cecilia Whitaker Vicente de Azevedo Alves Pinto) na década de 1970 e publicada em vários jornais e álbuns. O Pato tinha um traço simples, quase infantil, com a intenção de passar despercebido pelos censores, embora abordasse questões graves, como a repressão política e a crise econômica. Da mesma forma, o escritor gaúcho Luis Fernando Verissimo foi autor das tiras As Cobras e Família Brasil. Já o artista Renato Canini concebeu os quadrinhos do Dr. Fraud (o nome é uma alusão a Sigmund Freud, assim como remete a engano), um psicanalista louco, que contracena de forma intertextual com personagens dos comics como Charlie Brown, Alley Oop, entre outros.

Os quadrinhos humorísticos brasileiros da década de 1970 no tratavam apenas de polí- tica, mas também de sexualidade, um tema que sofreu com a censura. No entanto, havia maneiras de evitar os obstáculos à publicação. Frequentemente, os quadrinhos eróticos defenderam ideias e comportamentos ousados para una era marcada pelo conservadorismo e pela censura aos que iam além dos limites morais impostos pelo governo. Nas artes gráficas, Ziraldo Alves Pinto foi um dos artistas brasileiros que produziram histórias que tratavam de sexo, como a protetora Supermãe e o incansável Minierinho.

Durante a década de 1970, os artistas brasileiros também encontraram espaço em publicações comerciais, publicadas pelas principais editoras. Isso se deve ao fato de os artistas voltarem a recuperar o movimento em favor das histórias em quadrinhos brasileiras em revistas editadas no país. Ante o temor de que esta iniciativa se converteria em lei, as editoras começaram a utilizar materiais nacionais e até a criar publicações específicas para quadrinhos produzidos no Brasil. Este foi o caso da Editora Abril, que lançou em 1974 a revista CRÁS! 
De acordo com Vergueiro e Santos5, este título trazia, sobretudo em seus dois primeiros números, "uma mescla de estilos gráficos e de gêneros, como quadrinhos de terror, humor, aventura, infantis etc.". Artistas de diversas tendências, que vão desde o estilo clássico ao experimentalismo psicodélico típico da década de 1970, passaram por suas páginas. Entre eles, destacaram-se Renato Canini, com Kactus Kid (paródia de comics e películas americanas de western); Carlos Edgard Herrero, com seu Lobisomem, que não conseguia assustar ninguém; e Ruy Perotti, autor de Satanésio, um diabo que sofre em uma realidade difícil, pior que o inferno, ao lado do anjo Anjoca.

Outra importante editoria, RGE (atualmente Editora Globo), pertencente ao empresário Roberto Marinho, realizou um concurso para criar una revista de quadrinhos brasileiros. O ganhador foi o ítalo-brasileiro Primaggio Mantovi com o palhaço Sacarrolha, publicado em janeiro de 1972. Ambientada no circo ambulante Kabum, as histórias eram estreladas por um palhaço de bom coração. A mesma editora publicou tiras realizadas por artistas brasileiros na revista Gibi, como os personagens Chico Peste, do escritor Paulo Paiva e do desenhista Paulo César Munhoz; Olympo, de Xalberto (sátira aos deuses gregos); Zig e Zag, de S. Miguez (protagonizada por dois árabes que estão perdidos no deserto); e Ming- -Au (sobre um monge), idealizada por Sinfrônio de Souza Lima Neto.

Existem diversos quadrinhos humorísticos produzidos e publicados regionalmente no Brasil. Do Sul do país são as tiras de Radicci, do desenhista Carlos Henrique lotti, Rango, de Edgar Vasques, e A Dupla Sertanojo (uma sátira aos cantores populares), de Neltair Rebés Abreu, mais conhecido como Santiago. Radicci é habitante das Serras Gaúchas, um descendente da colônia italiana, grosseiro e autoritário, embora seja casado com uma mulher mandona e tenha um filho preguiçoso. Rango representa a parcela miserável da sociedade brasileira -o nome remete a comida, que ele raramente consegue. Sempre com fome, o protagonista e seu filho dormem em latas de lixo (metáfora da pobreza em que vivem) e perambulam por lixões em busca de migalhas que sobram da minoria privilegiada. Esses quadrinhos abordam temas como a opressão aos negros, a política e a economia nacional, a degradação do meio ambiente, etc.

Já as histórias da Turma do Xaxado possuem vários elementos da cultura do Nordeste do país -música, ambientação, modo de vestir dos personagens. De modo diferente do cangaceiro Chico Peste, idealizado em São Paulo, estes quadrinhos foram feitos por Antonio Cedraz, que nasceu em uma fazenda na Bahia. O protagonista é um garoto que vive em uma pequena cidade do interior. Entre seus amigos se encontra Arturzinho, o filho do fazendeiro, o que conduz a reflexões sobre as diferenças sociais, assim como questões como a seca.

Investigador dos quadrinhos, editor, militante de fanzines, na Paraíba, Henrique Magalhães foi também o criador do personagem Maria, lançada em 1975. Com a motivação inicial de encontrar um marido, sua função narrativa começou a girar em torno da situa- ção política e econômica do país, a defesa do quadrinho nacional e contra qualquer forma de intolerância seja em âmbito social ou em relação às preferências sexuais das pessoas.

O riso em um momento de crise (1985-1995)

Desde 1979, quando começou a abertura política, com a anistia aos militantes presos ou exilados, até princípios de 1985, quando o ciclo militar terminou com a posse do primeiro governo civil depois de duas décadas, o humor político se manteve presente, tanto em periódicos alternativos como nos meios de comunicação de massa. Mas 
o começo da década de 1980 se caracterizou também por outras mudanças, especialmente em relação ao comportamento e à cultura, especialmente em São Paulo. Foi o surgimento de una produção cultural independente.

Uma experiência inovadora nesse contexto foi posta em marcha em 1980 pelo desenhista Francisco Marcatti Junior. Com o dinheiro que recebeu de herança, comprou uma impressora off-set e fundou a editoria Pro-C, para a qual publicou histórias em quadrinhos, como Lodo e Mijo, cuja distribuição também era feita alternativamente em livrarias e cineclubes. As histórias de humor, absurdas e escatológicas, tratam principalmente de sexo bizarro, em relatos que estão cheios de palavras y referências vulgares aos resíduos do corpo humano.

Pequenos editores de São Paulo passam a publicar revistas impressas em papel de baixa qualidade, que abrigavam em suas páginas quadrinhos impressos, na maioria dos casos, em preto e branco, o que reduzia os custos. Diferentemente das publicações comerciais, estas revistas "alternativas" refletiam uma determinada posição política ou a resistência à visão dominante, privilegiavam a inovação artística e se tornavam outra opção para o pú- blico. Os autores colocavam sua visão de mundo e desenvolviam seu próprio estilo gráfico, que não repetiam os modelos estabelecidos pelos editores e distribuidores de quadrinhos mainstream.

Entre os diversos editores de São Paulo destaca-se a Circo Editorial, fundada em 1984 por Toninho Mendes. Esta editora publicou revistas como Chiclete com Banana, Piratas do Tietê, Striptiras, Geraldão e outros títulos. Os principais artistas que participaram destas publicações foram Angeli, Laerte, Glauco, Luiz Gê e Adão Iturrusgarai. Em suas histórias, a sátira política deu lugar à crítica social e de costumes. Vários desenhistas abordaram temas e os modismos da vida cotidiana da classe média da metrópole. O estilo gráfico destes autores refletia a influência dos comix underground feitos por Robert Crumb e Gilbert Shelton.

Como reflexo da situação política e social da década de 1980, de acordo com Santos6, o humor desses quadrinhos publicados nas revistas da Editorial Circo eram críticos dos costumes dos pequenos burgueses. As piadas colocavam em relevo a contradição, a idiossincrasia, a vaidade e a arrogância da classe média urbana. De forma diferente da teoria elaborada por Bergson7, a historieta humorística da Circo Editorial não objetivava controlar o comportamento para adaptá-lo às normas sociais, mas tinham a intenção de denunciar atitudes ridículas que são consideradas aceitáveis por uma sociedade que cultua a aparência, a hipocrisia e o consumismo.

Santos8 classifica os quadrinhos de humor publicados nas revistas da Circo Editorial baseado em objetos que suscitam o riso, os personagens e o ambiente em que ocorrem a narrativa cômica. Desta maneira, pode-se formular uma tipologia do humor do quadrinho da Circo Editorial com as seguintes características: humor urbano (que tem a cidade como fundo e como tema das histórias), humor político, humor erótico e humor comportamental. Embora uma destas características sobressaia em uma história em particular, outras podem ser acrescentadas a ela (o humor erótico, por exemplo, pode estar presente em uma tira ou uma história na qual prevalece o humor político).

São personagens recorrentes o punk Bob Cuspe, a mulher e solitária Rê Bordosa, o último macho Bibelô, os dois velhos hippies Wood e Stock, o ativista político Meiaoito, que não se ajusta à sociedade democrática, o narcisista Walter Ego, os anárquicos Piratas do Tietê (piratas que navegam pelo Rio Tietê, um dos maiores e mais poluídos da cidade), os habitantes do condomínio (o espaço característico da metrópole, que se converte 
em um microcosmo do Brasil), os caubóis homossexuais Rocky e Hudson, o solteiro Geraldão (que vive com sua mãe, mantendo com ela uma relação edípica), o Casal Neuras (que têm uma relação baseada no amor, na traição e no ódio).

Apesar da boa aceitação por parte dos leitores, a crise inflacionária levou ao fechamento da editoria em 1995. Contudo, o quadrinho humorístico publicado pela Circo Editorial teve o mérito de revelar, criticamente, os impasses e dilemas enfrentados pela classe média urbana brasileira nas décadas de 1980 e 1990, que luta com os dilemas existenciais típicos de uma vida monótona e intensamente dedicada ao consumo do supérfluo.

\section{O quadrinho de humor no século XXI}

Com o fim da maioria das revistas de quadrinhos brasileiras -à exceção dos títulos produzidos por Mauricio de Sousa-, os veteranos e os novos artistas de talento continuam a tradição de publicar tiras em jornais, que depois são reunidas em álbuns ou livros. Estas publicações costumam ser distribuídas em livrarias e lojas especializadas em quadrinhos, com tiragens baixas. Houve algumas tentativas de lançar revistas de quadrinhos de humor, seguindo o estilo underground, mas todos os títulos forma descontinuados depois de alguns números, como foi o caso de Cybercomix, cujas quatro edições chegaram às bancas em 1998, com obras de artistas nacionais estabelecidos (Laerte, Angeli, Adão Iturrusgarai, entre outros). Em 2005, a revista F. Humor teve três edições publicadas pelas editoras Gibiteca e Hy Brasil, editadas por Allan Sieber, Leonardo e Arnaldo Branco. Outra edição saiu em formato menor pela editora Conrad, que também foi responsável pela publicação de dois números da revista Crocodilo em 2003, um título que mesclou artistas estrangeiros e brasileiros, como Sieber. Este artista também participou do fanzine Tarja Preta, que totalizou sete edições até 2011.

Allan Sieber é um dos desenhistas que surgiram no século XXI. as tiras da série Preto no Branco, fortemente influenciadas pelo comix, são povoadas de personagens indignados (às vezes é o próprio autor caricaturizado), que estão fora da normalidade aceita pela sociedade. As histórias entituladas Talk to himself show apresenta um programa televisivo de entrevistas no qual o artista entrevista a si mesmo, expressa suas opiniões e faz autocrítica. Já as histórias intituladas Vida de Estagiário seguem um jovem que trabalha em uma agência de publicidade e precisa lidar com um chefe incompetente e com outros colegas -essas histórias viraram uma série televisiva.

Na mesma linha de Sieber, André Dahmer é autor da série Malvados, cujos personagens são cínicos e críticos e têm aparência de girassóis. Vivem situações estranhas e falam de religião, de relações desgastadas, bebida e de conflitos existenciais, normalmente empregando humor negro. O personagem Rei Emir Saad, conhecido como o Monstro de Zazarov, é o déspota e cruel monarca de um reino fictício da Europa. Seu nome e seu aspecto -traje roxo y barbas compridas- se referem aos czares russos. Na serie A cabeça é a ilha, os protagonistas são atormentados, como o jovem Ulisses, que roubou de um navio dez mil garrafas de vinho para esquecer sua amada Rebeca. Tanto Sieber como Dahmer passam com seus quadrinhos uma visão niilista.

Outro tipo de história em quadrinhos apareceu no século XXI: a tira poético-filosófica. Liberados da necessidade de ser engraçado e de obedecer à estrutura tradicional do quadrinho humorístico (que tem um elemento disjuntor que surpreende o leitor e causa o efeito cômico), o enfoque poético-filosófico aborda temas fora do comum, normalmente os dilemas existenciais. Este tipo de história, que foge da narrativa convencional, é influenciado pelo comix underground da década de 1970. Na definição de Santos Neto9 : 
As histórias em quadrinhos poético-filosóficas tendem a ser apresentadas em relatos que costumam romper com a linearidade narrativa convencional do quadrinho, usando, para tanto, de características criativas em relação ao traço do artista e às novas propostas de uso de requadros.

Este autor percebe três características que definem uma história em quadrinhos poético- -filosófica: "1. A intencionalidade poética e filosófica; 2 . as histórias são curtas e requerem uma leitura diferente da norma tradicional; 3. inovação da linguagem dos quadrinhos em relação aos padrões narrativos tradicionais"

Os quadrinhos poético-filosóficos produzidos por Laerte, por exemplo, têm uma história que pretende levar o leitor a refletir sobre um tema, mas nem sempre apresentam uma conclusão. Além disso, segundo Santos10, suas obras mostram uma procura formal em relação à arte e às convenções da linguagem quadrinística. No mesmo sentido, os irmãos Fabio Moon e Gabriel Bá elaboram para o diário Folha de S. Paulo uma tira cômica. Com o título Quase Nada, estas histórias estão além da norma convencional, se esquematizam em "dos andares". A estrutura narrativa se divide em duas etapas: a primeira encontra-se na parte superior das vinhetas, na qual um ou mais personagens tratam de um assunto, seja em pensamentos ou diálogos; e a segunda tem lugar na última vinheta, colocada na parte inferior, onde normalmente existe a presença de um animal que faz um comentário.

Se os quadrinhos impressos no Brasil se limitam às revistas com personagens infantis de Mauricio de Sousa, álbuns ocasionais (em geral com uma tiragem pequena e preço alto), ou publicações alternativas que duram poucos números, a Internet se converteu -sobretudo depois da entrada em funcionamento da Web 2.0- em um espaço para disseminar o trabalho de desenhistas, especialmente os principiantes. Blogs y sites da Web são utilizados para reunir obras de um ou mais artistas, permitindo o contato direto e imediato com os leitores, que publicam suas opiniões e críticas. As redes sociais também ajudam na circulação de quadrinhos. Contudo, a durabilidade do material é curta, já que pode ser retirada do espaço virtual a qualquer momento, enquanto que as histórias impressas são conservadas por mais tempo em coleções privadas ou públicas.

Os quadrinhos digitais podem utilizar ou não as características possibilitadas pelas ferramentas digitais (som, movimento, a paleta de cores, efeitos visuais). Mas, principalmente, os artistas não sofrem as restrições impostas aos meios de comunicação impressos: determinações editoriais arbitrárias, barreiras econômicas, limitações da distribuição e divulgação, prazos apertados, o alto custo de produção, o que aumenta o preço do produto, ou a necessidade de seguir um estilo consagrado ou um gênero que tem um grande atrativo para os leitores. O blog http://www.umsabadoqualquer.com/, por exemplo, foi criado em 2010 e apresenta os quadrinhos feitos pelo desenhista Carlos Ruas. As histórias têm como protagonista Deus e incluem a participação de outras divindades, assim como seu filho, com quem possui diferenças. O autor já publicou três coleções impressas destas tiras, sendo a mais recente em 2014, com o título Um sábado qualquer - Fique com os deuses!, o que prova que as histórias originalmente disponibilizadas no espaço digital também podem se converter em publicações impressas.

\section{Considerações finais}

Em um século e meio de quadrinhos de humor produzidos no Brasil, ainda são suscitadas algumas perguntas: Como é possível entender a relação entre o humor gráfico e a sociedade brasileira? Os ambientes, os 
personagens, com suas ações e discursos, representam a nação e seu povo (ou parte dele, ao menos)? Seja no humor ingênuo ou no mais crítico, o país está refletido nas histórias em quadrinhos de humor?

Ao responder a estas perguntas, se pode dizer que o objeto de estudo desta investigação, o quadrinho de humor produzido no país, é um retrato das limitações e das falhas do povo brasileiro, seja da elite, dos setores médios ou dos que mais sofrem com a desigualdade do sistema. Se o humor político, que surge nos momentos cruciais da história (na agonia da monarquia ou durante os momentos mais duros da ditadura na década de 1970), se centra naqueles que utilizam o poder para oprimir, critica os costumes depois da redemocratização dos anos 1980 e se volta a aqueles que levam uma vida medíocre-embalado pelas modas geradas e reforçadas pelos meios de comunicação massivos-, zombando dos consumidores vorazes e alienados, e até dos que assumem o papel de críticos desta situação. Qual é o rosto do brasileiro que o humor gráfico revela: do caipira ingênuo Nhô Quim, do traiçoeiro Amigo da Onça, do pobre e faminto Rango, do mentiroso Dr. Macarra, da mulher boêmia Rê Bordosa, ou do consumista Geraldão? Sem dúvida, cada um desses personagens representa uma das facetas de um povo heterogêneo. Tomados em conjunto, os quadrinhos de humor formam um painel da diversidade do Brasil -um termo que faz referência a diferentes pessoas quanto à origem, condição social e econômica, à localização geográfica e à cultura. A sensibilidade dos artistas para ver as contradições de ser brasileiro, com o tempo, em vez de causar o efeito cômico, o riso, leva o lictor a refletir sobre sua realidade cada vez mais complexa.

Do ponto de vista estético, as histórias em quadrinhos humorísticas realizadas no Brasil apresentam tanto desenhos realistas (como no trabalho de Angelo Agostini) como de caricatura (a maioria, a exemplo das histórias infantis). La presença/ausência de cenário depende de estilo do autor, assim como o uso das linhas de expressão. E a influência do comix underground, desde a década de 1970, deu lugar a uma representação pictórica "mais suja", quer dizer, com manchas de tinta deliberadas em várias partes das vinhetas, estilo que reforça o tom irônico, de oposição e alternativo do humor gráfico brasileiro.

\section{Notas}

Cirne, M. (1982). Uma introdução política aos quadrinhos. Rio de Janeiro: Achiamé, p. 11.

Balaban, M. (2009). Poeta do lápis: sátira e política na trajetória de Angelo Agostini no Brasil Imperial. Campinas: Unicamp, p. 28.

Silva, M. A. da (1989). Prazer e poder do Amigo da Onça. Rio de Janeiro: Paz e Terra, pp. 91-92.

Cirne, M. (1990). História e crítica dos quadrinhos brasileiros. Rio de Janeiro: Europa / Funarte, p. 72.

Vergueiro, W.;

Santos, R. E. dos (2009). Crás! Comic Book: Brazilian comics and the publishing industry, International Journal of Comic Art, Vol. 11, n.1. Drexel Hill: IJOCA, pp. 247-261. Santos, R. E. dos (2011). Humor, crítica e erotismo nos quadrinhos brasileiros. In: Vergueiro, W.; Santos, R. E. dos (orgs.). A História em Quadrinhos no Brasil: análise, evolução e mercado. São Paulo: Laços, p. 156.

Bergson, H. (1993). O riso - ensaio sobre o significado do cômico (2ed.). Lisboa: Guimarães Editores. 
Santos, R. E. dos (2011). Humor, crítica e erotismo nos quadrinhos brasileiros. In: Vergueiro, W.; Santos, R. E. dos (orgs.). A História em Quadrinhos no Brasil: análise, evolução e mercado. São Paulo: Laços, p. 159.

Santos Neto, E. dos (2009). O que são histórias em quadrinhos poético-filosóficas? Um olhar brasileiro. Revista Visualidades, Vol. 7, n. 1. Goiânia: Universidade Federal de Goiás, pp. 68-99.

Santos, R. E. dos. (2014). HQs de Humor no Brasil: variações da visão cômica dos quadrinhos brasileiros (18642014). Porto Alegre: EDIPUCRS, p. 112.

Abstract: This work is the result of a study carried out in the Programa de Pós-graduação em Comunicação da Universidade Municipal de São Caetano do Sul (USCS) in Brazil, whose objective was to understand how the country's political and social trajectory has been portrayed by Brazilian artists since the nineteenth century to the present, through humor. To achieve this goal, documentary research and content and context analysis were carried out, as well as the division into five major periods of the country's history and the production of comics.

Key words: Brazilian comics - Graphic humor - Politics - Brazil.

Resumo: Este trabalho é o resultado de um estudo realizado no Programa de Pós-gradua- ção em Comunicação da Universidade Municipal de São Caetano do Sul (USCS), no Brasil, cujo objetivo foi entender como a trajetória política e social do país foi retratada por artistas brasileiros desde o século XIX até a contemporaneidade através do humor. Para alcançar este objetivo, uma pesquisa documental e uma análise de conteúdo e de contexto foram realizadas, assim como a divisão em cinco grandes períodos da historia do país e da produção de histórias em quadrinhos.

Palavras chave: Quadrinhos brasileiros - humor gráfico - desenho humorístico - história social e política - Brasil.

[Las traducciones de los abstracts al inglés y portugués fueron supervisadas por el autor de cada artículo]

O Brasil através das histórias em quadrinhos de humor fue publicado de la página 153 a página167 en Cuadernos del Centro de Estudios de Diseño y Comunicación №74 